\title{
Investigation of temperature and residual stresses field of submerged arc welding by finite element method and experiments
}

\author{
M. R. Nezamdost ${ }^{1}$ - M. R. Nekouie Esfahani ${ }^{2}$ - S. H. Hashemi ${ }^{1}$ - S. A. Mirbozorgi ${ }^{1}$
}

Received: 17 July 2015 / Accepted: 12 February 2016/Published online: 27 February 2016

(C) The Author(s) 2016. This article is published with open access at Springerlink.com

\begin{abstract}
This article reports on a numerical and experimental investigation to understand and improve computer methods in application of the Goldak model for predicting thermal distribution in submerged arc welding (SAW) of APIX65 pipeline steel. Accurate prediction of the thermal cycle and residual stresses will enable control of the fusion zone geometry, microstructure, and mechanical properties of the SAW joint. In this study, a new Goldak heat source distribution model for SAW is presented first. Both $2 \mathrm{D}$ and $3 \mathrm{D}$ finite element models are developed using the solution of heat transfer equations in ABAQUS Standard implicit. The obtained results proved that the $2 \mathrm{D}$ axi-symmetric model can be effectively employed to simulate the thermal cycles and the welding residual stresses for the test steel. As compared to the $3 \mathrm{D}$ analysis, the $2 \mathrm{D}$ model significantly reduced the time and cost of the FE computation. The numerical accuracy of the predicted fusion zone geometry is compared to the experimentally obtained values for bead-on-plate welds. The predictions given by the present model were found to be in good agreement with experimental measurements.
\end{abstract}

Keywords Submerged arc welding (SAW) · API X65 steel · Thermal cycle $\cdot$ Finite element method (FEM) $\cdot$ Goldak model

\section{R. Nekouie Esfahani}

m.esfahani@lboro.ac.uk

1 Department of Mechanical Engineering, The University of Birjand, PO BOX 97175-376 Birjand, Iran

2 Laser Engineering Group, Wolfson School of Mechanical and Manufacturing, Loughborough University, Loughborough LE11 3TU, UK

\section{Introduction}

Because of its high quality and reliability, submerged arc welding (SAW) is employed extensively in industry to join metals for the manufacture of energy transportation pipes applied for different applications [1-3]. The service performance of SAW joints is dependent on the fusion zone microstructure, which itself is dependent on the weld thermal cycle and alloying elements [4]. However, it is challenging and costly to quantify the thermal cycles and temperature fields by pure experimental studies. In addition, the results of experimental works are often limited to welding technology, work-piece geometry, and welding set-up and cannot be used if the test parameters are varied. Therefore, FEA analysis can be employed to effectively predict the welding temperature field, cooling rate, microstructure and residual stresses.

A schematic diagram of a SAW welding is given in Fig. 1. A moving arc of sufficient energy input is incident upon the work-piece surface at a constant welding speed. A fraction of the incident energy is absorbed by the work-piece leading to the formation of a fusion zone. As the electrode passes over the work-piece, the melt pool extends along the scanning direction and solidifies soon after the electrode and contact tip moves away.

Several numerical [5-17] and experimental investigations $[1,2,18-22]$ of arc welding have been reported by various researchers. Rosenthal [23] first proposed a mathematical model of a moving heat source under the assumption of quasi-steady state; however, as many researchers have discussed, Rosenthal's analysis (that assumes either a point, line, or plane source of heat) has major error for temperatures in or near the fusion and heat-affected zones [24]. After his work, various studies have been carried out on submerged arc welding to investigate the whole SAW process using numerical simulations. Goldak et al. [24] established a 
Fig. 1 Schematic diagram of submerged arc welding process

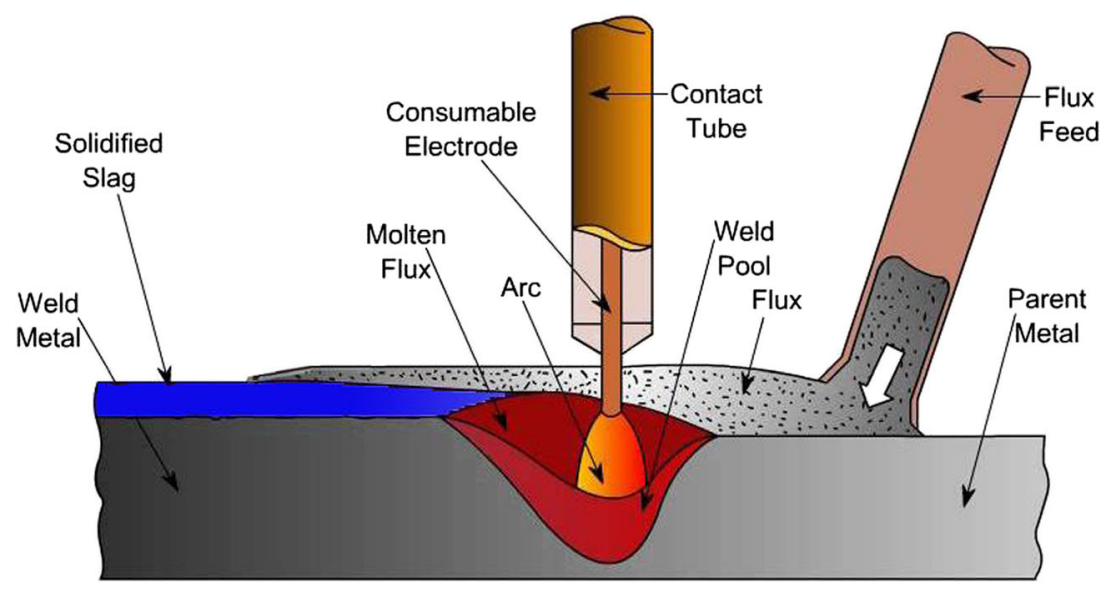

mathematical double ellipsoid model for the welding heat source with versatility to be used for analysing the thermal history in both shallow and high penetration welds. His model provided an effective and reliable solution for calculation of the thermal history in weld. Andersson [25] developed a 2D FE approach to study the distributions of residual stress in the top and bottom surfaces of the parent plate near the weld during a butt SAW process. The phase transformation during cooling was taken into account employing a volumetric dilatation technique, which was proposed to be of primary importance to the residual stress analysis of weldment. FE results were compared to experimental measurements and are showed that despite of good agreement for thermal history, there are differences in calculated and measured values of residual stresses in the weldment. Marimuthu et al. [26] used ANSYS package to predict surface topology of weld bead and subsequent structural performance. A sequentially coupled thermal-mechanical analysis approach was adopted in which the weld bead surface profile and thermal history were calculated using a 3D CFD model. This model then applied into a finite element method (FEM) scheme for further structural analysis. They discussed that the main driving force for weld bead surface geometry formation is the Marangoni effect. Increasingly, commercial software packages such as ABAQUS [27] have been applied to study various welding processes [14, 28-30]. Michaleris and DeBiccari [30] employed ABAQUS to calculate welding-induced distortion and to study the structural integrity of large and complex structures. A decoupled thermalmechanical analysis approach was developed where the welding-induced residual stresses were calculated based on a 2D FE model and then applied to a 3D FE model for structural analysis. Sharma et al. [16] suggested and validated a volumetric heat source model of twin-wire SAW by using different electrode diameters and polarities. It has been found that the heat source model parameters for twin-wire welding are substantially different from the single-wire welding. Moreover, they showed that the heat source model parameters also depend upon welding parameters. Heat transfer and cooling rate of the fusion zone for SAW-T welding process were investigated using finite element methods by Kiran et al. [17]. They showed that welding cooling rates decreases with higher welding current. Wen et al. [14] developed the 2D and 3D FE models to predict welding-induced residual stresses and strains using FE package ABAQUS [27]. The heat transfer in the fusion and heat affect zones were investigated and linked to their structural analysis. Kim et al. [31] obtained the fluid dynamics and temperature distribution for different driving forces during tungsten arc welding (GTAW). Recently, Esfahani et al. [4, 32] carried out a research on microstructure and mechanical properties of dissimilar laser welding. They reported that the alloying concentration and consequent microstructure of the fusion zone is highly dependent on the fluid flow driven by thermal gradient, and hence accurate prediction of thermal gradient in fusion zone is of great importance. Until now, however, the significance of using two Goldak's double ellipsoidal heat sources in the SAW welding of APIX65 pipeline steel has not been fully

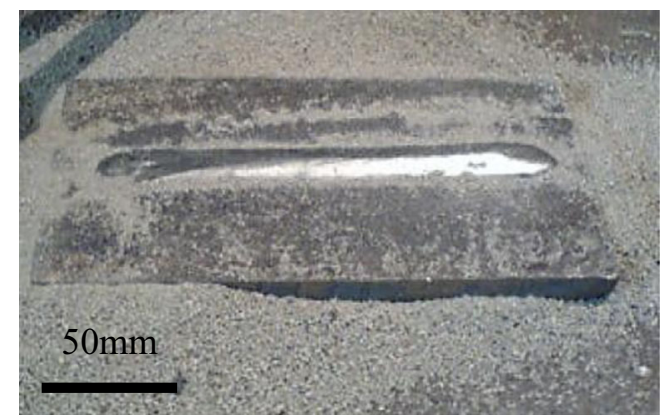

Fig. 2 Typical SAW plate weld bead with a controlled welding process (400 A, $34 \mathrm{~V}$, speed $1200 \mathrm{~mm} / \mathrm{min}$ ) 
investigated. In particular, the heat source modelling techniques to increase the accuracy of the temperature and stress prediction require careful consideration.

In this work, a 2D axi-symmetric and a 3D FE model of transient thermal analysis were developed based on two Goldak' s double ellipsoidal heat sources to achieve higher accuracy prediction of temperature and stress in molten pool and heat-affected area (HAZ) of SAW welding. The thermophysical material properties were taken into account. The temperature field, residual stresses and fusion zone profile were predicted for both $2 \mathrm{D}$ and $3 \mathrm{D}$ scenarios. The calculated thermal cycle and weld geometry in the fusion zone were compared with experimental results obtained under similar parameters.

\section{Experimental procedure}

The material used in this study was API X65 steel plates. The S2MO welding wire with 3.2-mm diameter and AMA OP 139 welding flux were employed for the welding process. The chemical compositions of the base metal welding wire and flux are given in [33, 34]. A weld bead on the plate was deposited using submerged arc welding process with $400 \mathrm{~A}$, $34 \mathrm{~V}$, and $1200 \mathrm{~mm} / \mathrm{min}$ welding speed (Fig. 2). The size of the metal plate was 200 -mm length $\times 100$-mm width with 14.3-mm thicknesses. In order to obtain geometry of weldment (weld width, weld depth, and length) and HAZ, the weld cross section was polished up to $1 \mu \mathrm{m}$ and etched using Nital $(5 \%)$ reagent.

\section{Formulation and grid structure}

\subsection{Thermal analysis}

The FEA analysis was developed in ABAQUS software to model welding temperature fields for submerged arc beadon-plate weldment. The problem of heat conduction in the weldment has been solved using heat transfer analysis to obtain thermal distribution histories. The formulation considers the contributions of the transient temperature field, as well as temperature-dependent thermo-physical properties. Figure 3 shows the initial mesh employed for the FEA analysis of

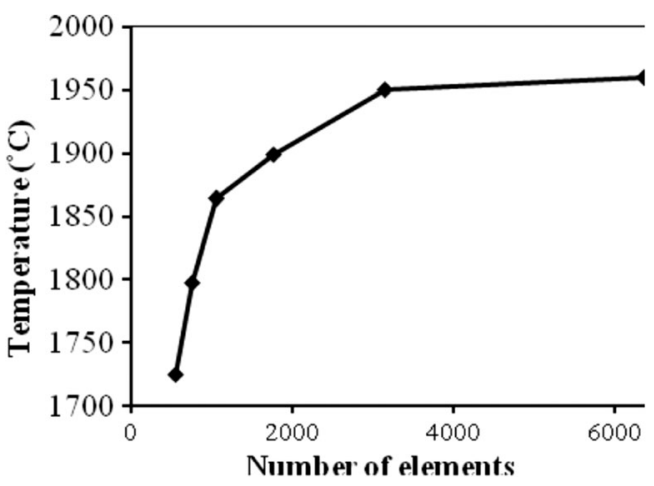

Fig. 4 Comparison of temperature distribution sensitivity (obtained from 3D FE model) to numbers of elements

SAW process. Because of the symmetry condition, only half of the welded plate is modelled for both 2D and 3D cases (Fig. 3). Filler material has also been taken into account for butt-joints of API X65 as can be seen in Fig. 3b. A variable spacing grid system with a fine grid near the heat source and a course grid away from the heat source has been used. The 3D computational domain in FEA model has the same dimension as the experimental sample and is modelled by 19430 eight-node brick solid elements of type DC3D8. The 2D computational domain however is modelled by 19430 four-node brick solid elements of type DC2D4 (Fig. 3a). Since the mesh size has significant role on calculation of temperature distribution, the peak temperature is used as the key parameter to measure the sensitivity of the analysis. Figure 4 shows the peak temperature versus the maximum number of elements. It can be seen from the figure that at 6000 elements, the variation of peak temperatures falls to less that $2 \%$. However, despite of stabilised temperature variation at 6000 elements, stress variation has stabilised around 19430 elements. As a result, a smoother thermal history and tension field are obtained at 19430 elements. The ambient temperature was set at $25{ }^{\circ} \mathrm{C}$. The thermo-mechanical properties $[35,36]$ of API X65 used in the analysis are detailed in Table 1. The properties of filler wire are assumed to be same as the API X65 due to its significantly higher dilution rate in weld.

A code written as subroutine (DFLUX) in the FORTRAN programming language was used in order to apply a heat flux as a transient boundary condition on the top surface of the
Fig. 3 Finite element mesh of SAW for APIX65 steel: for the 2D model (a) and for the 3D model (b)

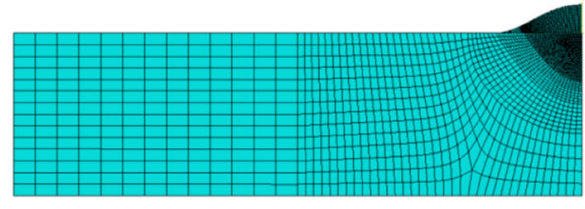

(a)

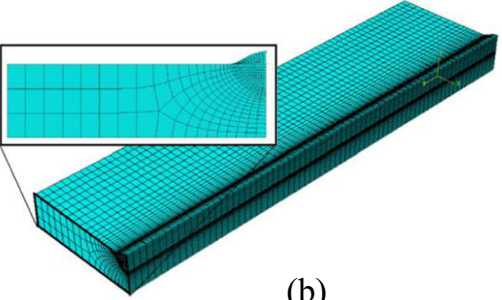

(b) 
Table 1 Temperature-dependent thermal properties of the substrate [37]

\begin{tabular}{|c|c|c|c|c|c|c|c|}
\hline \multirow{2}{*}{$\begin{array}{l}\text { Temperature } \\
\text { (K) }\end{array}$} & \multicolumn{2}{|c|}{ Thermal properties } & \multicolumn{5}{|c|}{ Mechanical properties } \\
\hline & $\begin{array}{l}\text { Conductivity } \\
(\mathrm{W} / \mathrm{m} \cdot \mathrm{K})\end{array}$ & $\begin{array}{l}\text { Specific heat } \\
10^{6}\left(\mathrm{~J} / \mathrm{m}^{3} \cdot \mathrm{K}\right)\end{array}$ & $\begin{array}{l}\text { Young modulus } \\
(\mathrm{GPa})\end{array}$ & $\begin{array}{l}\text { Tangential modulus } \\
10^{-1}(\mathrm{MPa})\end{array}$ & Poisson ratio & $\begin{array}{l}\text { Expansion } \\
10^{-6}(\mathrm{~K})\end{array}$ & $\begin{array}{l}\text { Yield stress } \\
(\mathrm{MPa})\end{array}$ \\
\hline 298 & 60.0 & 31.9 & 206 & 94.5 & 0.29 & 12.5 & 500 \\
\hline 323 & 59.5 & 32.1 & 204 & 93.5 & 0.30 & 12.7 & 490 \\
\hline 373 & 58.8 & 32.7 & 203 & 90.0 & 0.31 & 13.0 & 465 \\
\hline 473 & 55.4 & 33.8 & 198 & 81.0 & 0.32 & 13.5 & 428 \\
\hline 573 & 50.5 & 34.8 & 191 & 69.0 & 0.33 & 13.2 & 385 \\
\hline 673 & 45.9 & 36.0 & 180 & 37.5 & 0.34 & 13.4 & 335 \\
\hline 773 & 41.2 & 37.2 & 167 & 18.5 & 0.35 & 13.5 & 260 \\
\hline 973 & 33.3 & 41.8 & 53 & 9.0 & 0.37 & 13.9 & 170 \\
\hline 1173 & 28.5 & 35.4 & 25 & 4.0 & 0.39 & 11.0 & 105 \\
\hline 1373 & 30.2 & 36.0 & 13 & 1 & 0.40 & 13.0 & 29 \\
\hline 1573 & 32.1 & 36.5 & 2 & - & 0.44 & 14.5 & 6 \\
\hline 1773 & 36.6 & 38.3 & 1 & - & 0.48 & 17.8 & - \\
\hline 2023 & 39.9 & 39.2 & - & - & 0.48 & - & - \\
\hline
\end{tabular}

weld. A moving volumetric heat source has been considered for modelling of welding arc, based on the double ellipsoidal distribution proposed by Goldak [24] (Fig. 5), which is expressed by the following equations. For the front heat source:

$q_{f}=\frac{6 \sqrt{3} \eta Q f_{f}}{\pi \sqrt{\pi} a b c_{f}} e^{-3\left(\frac{x^{2}}{a^{2}}+\frac{y^{2}}{b^{2}}+\frac{z^{2}}{c_{f}^{2}}\right)}$

And for the rear heat source:

$q_{r}=\frac{6 \sqrt{3} \eta Q f_{r}}{\pi \sqrt{\pi} a b c_{r}} e^{-3\left(\frac{x^{2}}{a^{2}}+\frac{y^{2}}{b^{2}}+\frac{z^{2}}{c_{r^{2}}}\right)}$

where $Q$ is the welding heat source power, $x, y$ and $z$ are the local coordinates of the double ellipsoid model aligned with the weld line. The parameters $a, b, C_{r}$ and $C_{f}$ are associated to the features of welding heat source and were calibrated with

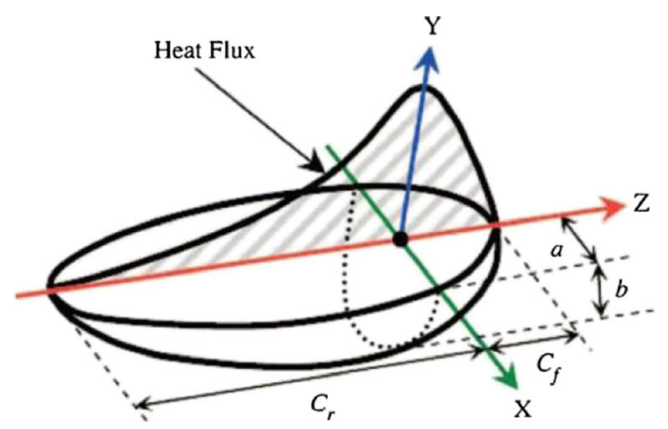

Fig. 5 Schematic diagram of Goldak model [38] respect to the measured size of the fused zone (weld depth, weld width and length in front and back half of the weld). These parameters are obtained from experimental analysis of the fusion zone and are adjusted to create a desired melted zone according to the welding conditions. In addition, the moving coordinate system is assumed to be matched with the stationary coordinate $C$ at time $t=0$ for $f_{i}$ for $i=f$, rindicates the percentage of the total welding power $Q$ in the front $\left(f_{f}\right)$ or rear quarter $\left(f_{r}\right)$ of the two ellipsoidal regions and is linearly related to the dimensions of these regions by Goldak [24, 39, 40]:

$f_{i}=\frac{2 c_{i}}{c_{f}+c_{r}}, \quad(i=f, r)$

It is worth mentioning that thermal gradient is far superior in the front of the arc compare to that of the back. The arc efficiency $\eta$ is assumed to be $90 \%$ for the SAW welding process $[15,41,42]$. These parameters are detailed in Table 2 for both weld reinforcement and fusion zone. In order to have a higher accuracy in prediction of thermal distribution, two Goldak's double ellipsoidal heat sources are used in this

Table 2 Goldak models parameters used in FEA analysis for weld reinforcement and fusion zone

\begin{tabular}{llllllll}
\hline Goldak parameters & $\begin{array}{l}a \\
(\mathrm{~mm})\end{array}$ & $\begin{array}{l}b \\
(\mathrm{~mm})\end{array}$ & $\begin{array}{l}c_{f} \\
(\mathrm{~mm})\end{array}$ & $\begin{array}{l}c_{r} \\
(\mathrm{~mm})\end{array}$ & $f_{f}$ & $f_{r}$ & $q$ \\
\hline Weld reinforcement & 5.5 & 5 & 5 & 23 & 1.64 & 0.36 & $0.35 \mathrm{VI}$ \\
Fusion zone & 5.5 & 2.5 & 5 & 23 & 1.64 & 0.36 & $0.65 \mathrm{VI}$ \\
\hline
\end{tabular}




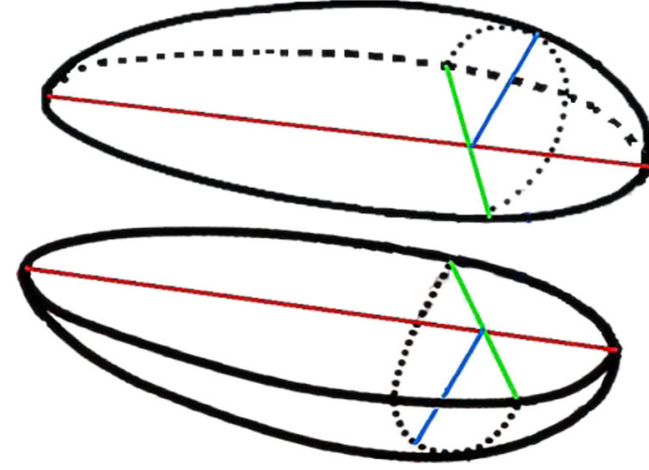

Fig. 6 Schematic diagram of the two proposed Goldak models

paper, one for the fusion zone and the other one for the deposited flux (weld reinforcement, excess of weld). The latter is modelled inversely to the one used for fusion zone as presented in Fig. 6.

In the thermal analysis, the transient temperature field $T$ is a function of time $(t)$ and the spatial coordinates $(x, y, z)$, and is determined by the three-dimensional nonlinear heat transfer equation:

$\rho c \frac{\partial T}{\partial t}(x, y, z, t)=-\nabla \cdot \vec{q}(x, y, z, t)+Q(x, y, z, t)$

where $\rho$ is the density of the materials, $c$ is the mass-specific heat capacity, $T$ is the current temperature, $\vec{q}$ is the heat flux vector, $Q$ is the internal heat source rate, $x, y$ and $z$ are the coordinates in the reference system, $t$ is the time, and $\nabla$ is the spatial gradient operator.

The non-liner isotropic Fourier heat flux constitutive equation is used [28]:

$\vec{q}=-k \nabla T$

where $k$ is the temperature-dependent thermal conductivity. On the boundary or the surfaces of the work-piece, convection and radiation in heat transfer are responsible for heat loss to the ambient. To simulate the combined thermal boundary condition and avoid complexities with radiation modelling, a user-defined subroutine was developed. The total temperature-

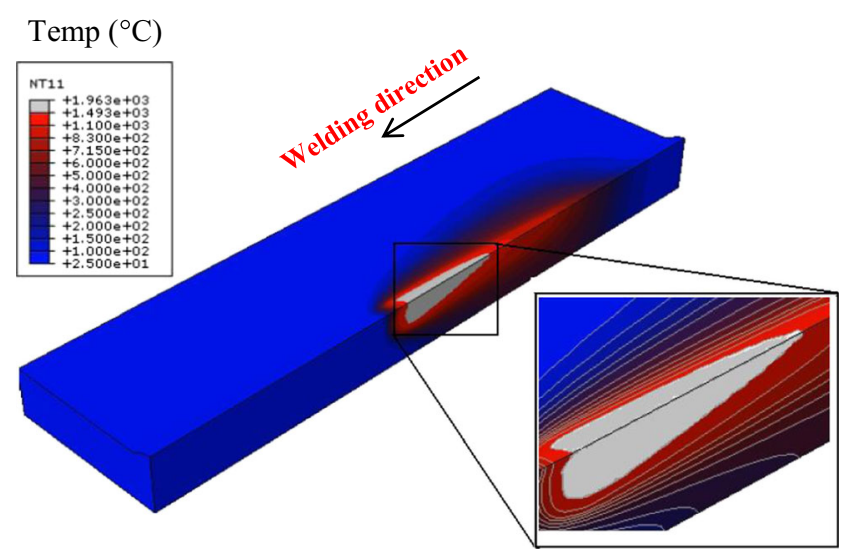

Fig. 8 Welding direction and temperature fields at the middle of weld line

dependent heat transfer coefficient is provided by Eq. (5) [28, 43]:

$h=\left\{\begin{array}{l}=0.68 T \times 10^{-8}\left(\mathrm{~W} / \mathrm{mm}^{2}\right) \quad 0<T<500^{\circ} \mathrm{C} \\ =(0.231 \mathrm{~T}-82.1) \times 10^{-6}\left(\mathrm{~W} / \mathrm{mm}^{2}\right) \mathrm{T}>500^{\circ} \mathrm{C}\end{array}\right.$

where $h$ is the heat transfer coefficient and $T$ is the temperature in degree Celsius. For the purpose of fusion zone and HAZ geometry prediction, a user defined field (USDFLD) subroutine was developed to determine the peak temperatures in the FE thermal analysis. The subroutine can keep a record of the peak temperatures by equating a state field variable in the subroutine to the temperature whenever the latter is on the rise. The state field variable can then be plotted from the results file as the peak temperature throughout the process of welding. In this code, the melting point of the material is defined as $1493{ }^{\circ} \mathrm{C}$. Based on Francis et al. [44], there are two critical regions in $\mathrm{HAZ}$ where the grain coarsening and phase transformation lead to major variation in microstructure and service performance of the weld. Therefore, the HAZ is differentiated in the code to grain coarsening region (HAZ 1) where the material has been heated to temperatures in the range of $1100-1440{ }^{\circ} \mathrm{C}$, and grain-refining region (HAZ 2) in which the material has been heated to temperatures in the range of $823\left(\mathrm{AC}_{3}\right)-1100{ }^{\circ} \mathrm{C}$ [44].
Fig. 7 Comparison of simulated (left side) and experimental (right side) weld bead cross section profiles: from FE model (a) and from experiment (b)

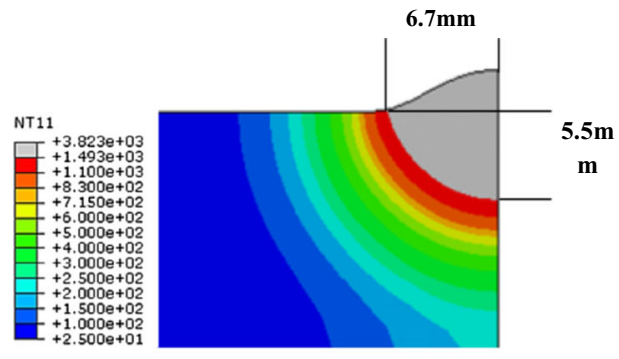

(a)

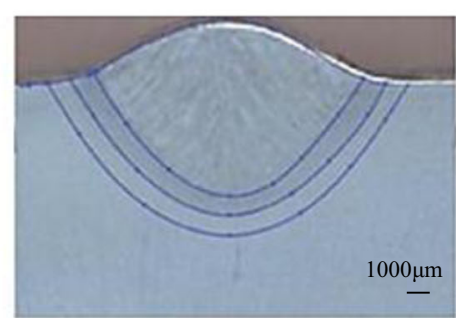

(b) 


\subsection{Mechanical analysis}

The stress distortions in weld are mainly caused by the thermally induced expansion and shrinkage and phase transformation-induced volume change. The residual stresses from phase transformation have not taking into consideration in this study. The residual stresses are calculated by employing the temperature distribution obtained from thermal analysis as input data. The material properties relevant to residual stresses are Young's modulus, yield strength, Poisson's ratio and the coefficient of thermal expansion. By considering the elasticplastic material properties, the total strain in the SAW weld can be decomposed into three components as given by [45]:

$\varepsilon=\varepsilon^{e}+\varepsilon^{p}+\varepsilon^{t}$

Where $\varepsilon^{e}, \varepsilon^{p}$ and $\varepsilon^{t}$ are elastic strain, plastic strain and thermal strain, respectively. Elastic strain is modelled using the isotropic Hooke's law with temperature-dependent Young's modulus and Poisson's ratio. The thermal strain is calculated using temperature-dependent coefficient of thermal expansion. For the plastic strain, a plastic model is employed with von Mises yield criterion, temperature-dependent mechanical properties and linear kinematic hardening model. Kinematic hardening is considered because material points undergo both loading and unloading in the welding process, which has been widely used in the welding residual stress simulation $[28,46]$. The boundary conditions taken into consideration in the mechanical analysis assume that one edge of the butt joint is fixed, and the other one is only transversely shrinkage free.

\section{Results and discussion}

The main objective of this research is to develop a FEA model that is capable of predicting the SAW thermal cycle and residual stress with higher accuracy compare to the available results in literature. To do this, a two Goldak heat sources are developed for fusion zone and weld reinforcement. Using the modified heat source, the 2D and 3D models are developed,

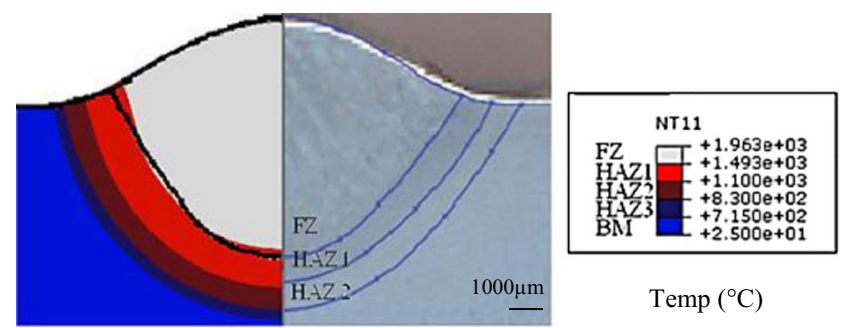

Fig. 10 Comparison between the proposed Goldak model prediction (left) and test fusion zone geometry (right)

and their thermal distribution and residual stresses are compared with each other.

Figure 7a shows the weld bead temperature distribution using the Goldak model. Considering the melting point of the steel as $1493{ }^{\circ} \mathrm{C}$, it is evident from etched cross section of weld (Fig. 7b) that the fusion zone width and depth are predicted somewhat wider and deeper than the experiments. The reason for that is mainly because the calculation does not consider the amount of the energy which is used to melt the deposited wire into the fusion zone. This simplification will result in (a) higher peak temperature in fusion zone $\left(3800{ }^{\circ} \mathrm{C}\right)$, (b) larger geometry for fusion zone and HAZ, and consequently lack of accuracy of the model. Therefore, two Goldak's double ellipsoidal heat sources are used in this paper, one for the fusion zone and the other one for the deposited flux (weld reinforcement, excess of weld).

\subsection{Simulated results of 3D model}

The welding direction and temperature contours are shown in Fig. 8. Welding started from one end of the work-piece, and after sweeping along the weld line, it ends at the other end. From this figure, it can be also observed that the maximum temperature at the fusion zone is about $2000{ }^{\circ} \mathrm{C}$.

Figure 9a shows peak temperature distribution on weld surface versus distance from the weld centre line for various time steps. As can be seen from the figure, the temperature of the points close to weld centre line decreases as the time increases. However, the temperature of the points away from the
Fig. 9 Temperature distribution versus distance from the weld centre line (a): on weld surface (b) through the thickness

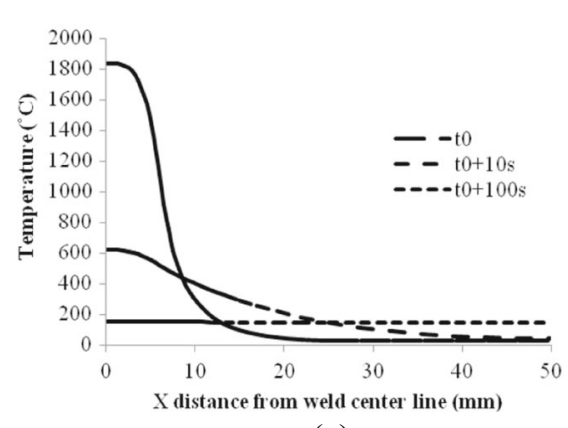

(a)

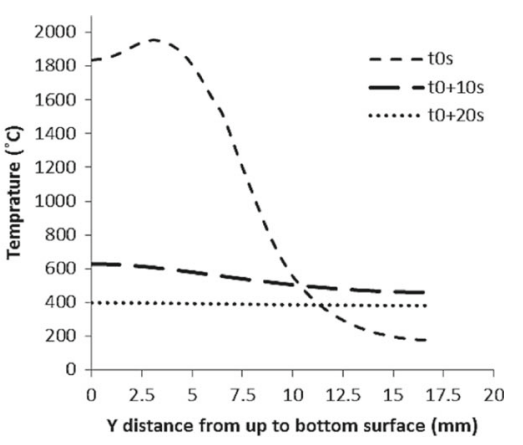

(b) 
Fig. 11 Stress field distribution (MPa) of the weldment after solidification: transverse direction (perpendicular to welding direction) (a), along thickness (b), longitudinal direction (in welding direction) (c), and von Mises stresses (d)

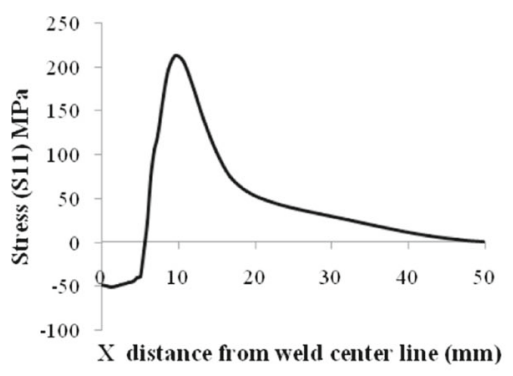

(a)

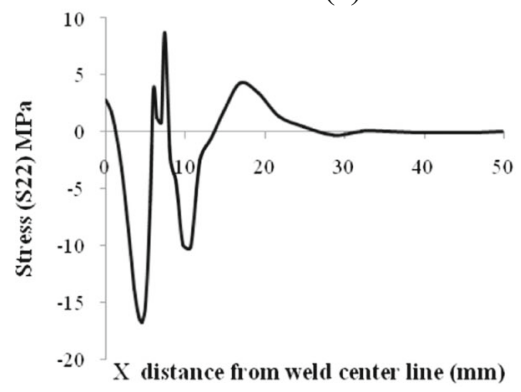

(c)

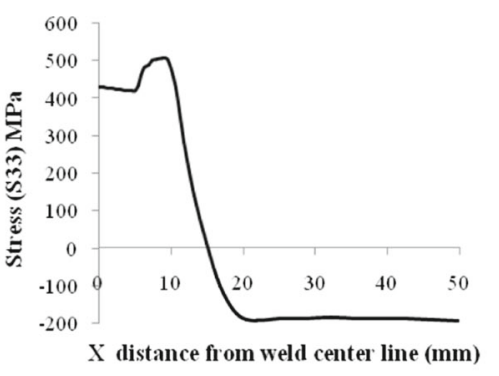

(b)

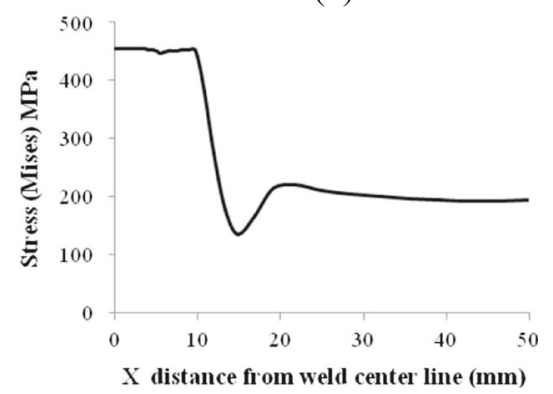

(d) weld increases by increasing the time. One reason for the temperature rise can be attributed to higher thermal gradient of the close region to fusion zone which consequently results in faster undercooling and sooner temperature drop in comparison to the regions that are away from the weld boundary (which experience less thermal gradient and heat transfer).
Fig. 12 Residual stresses on the upper surface of the 3D model: transverse residual stress distributions (MPa) (a), longitudinal residual stress (b), through thickness residual stresses (c)

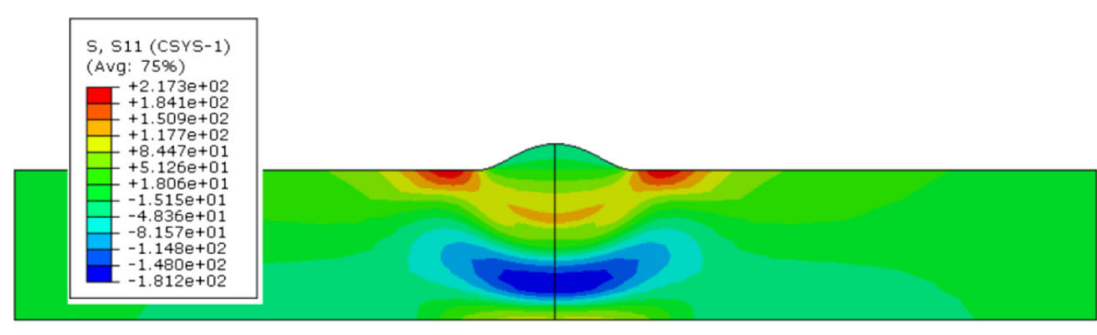

(a)

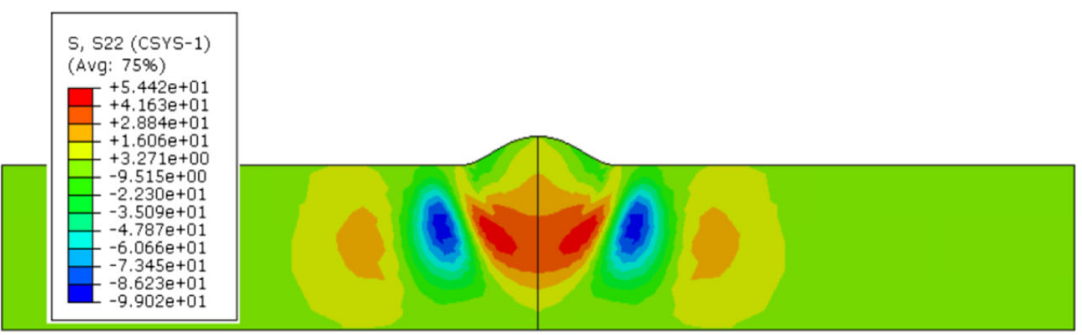

(b)

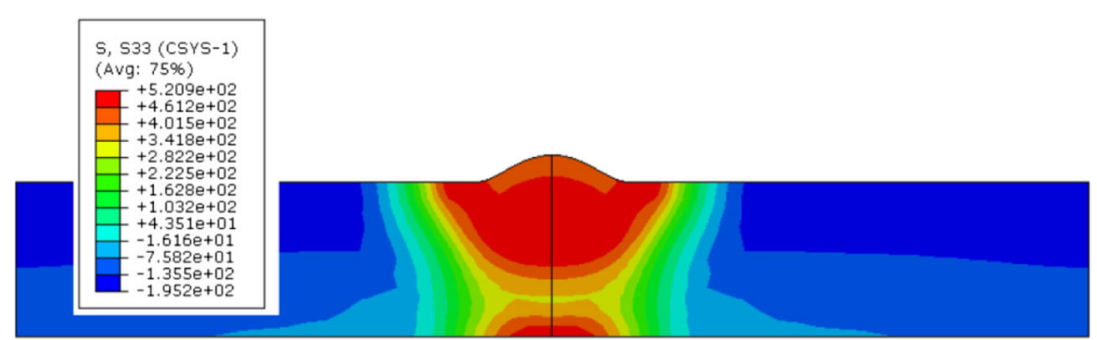

(c) 
Another reason behind temperature differences may be attributed to the effect of phase transformation on carbon steel. Rate of solid state phase transformation in the different regions away from the steel's fusion absorbs a proportion of heat source energy [47]. It is also worth mentioning that the rate at which the temperature gradient becomes constant through the thickness (Fig. 9b) is higher than the corresponding rate on the surface (Fig. 9a), (20(s) through the thickness in comparison to that of $100(\mathrm{~s})$ for the surface). Therefore, the weld thickness plays a more important role than the weld width in undercooling of the joint. Figure 10 shows the fusion zone and HAZ geometry obtained by FEA analysis (modified Goldak model) and experimental analysis. The weld and HAZ geometry in the model is obtained using a subroutine (USDFLD) in the model as discussed earlier. From this figure, it can be noticed that both the fusion zone and the HAZ geometry at each location are in very good agreement with the experimental measurements.

\subsection{Results of mechanical analysis}

The predicted distribution of transverse residual stresses for APIX65 steel at the position of $z=180 \mathrm{~mm}$ is presented in Fig. 11a. As can be seen, the stress is $-50 \mathrm{MPa}$ at fusion zone due to compressive forces in this region, and then it rise to $212 \mathrm{MPa}$ in HAZ as a result of tensile stress of weld region during solidification. Figure $11 \mathrm{~b}$ illustrates the longitudinal residual stress for the fusion zone and HAZ. The results show an almost similar trend to that of transverse stresses though the magnitude of the longitudinal stresses are about twice the maximum value of transverse residual stresses. The average stress is $420 \mathrm{MPa}$ in fusion zone as a result of tensile force from the surrounding metals which creates tensile stresses in the region, and the maximum stress occurs in the steel HAZ for the value of $504 \mathrm{MPa}$. The results also show that by moving away from fusion zone and HAZ, the stress decreases with significantly steeper trend and reach to the compressive stress value of $-200 \mathrm{MPa}$ in the base metal to balance the tensile stresses in fusion zone. The stress distribution along the thickness is shown in Fig. 11c. This figure shows the minimum stress among the other directions $(-17 \mathrm{MPa}$ in fusion zone and $0 \mathrm{MPa}$ in base metal). The von Mises equivalent residual stresses (presented in Fig. 11d) has the average of $450 \mathrm{MPa}$ $\left(\sim 0.84\right.$ of $\left.\sigma_{y}\right)$ in fusion zone and HAZ. This value decreases to $200 \mathrm{MPa}$ in the base metal. The distributions of transverse, thickness and longitudinal stresses fields in the $x-y$ plane are displayed in Fig. 12a, b c, respectively.

\subsection{D axi-symmetric model}

The 2D finite element model and weld passes are shown in Fig. 13. The numerical analysis procedure employed in 2D model is the same as the 3D model. In welding simulation, it

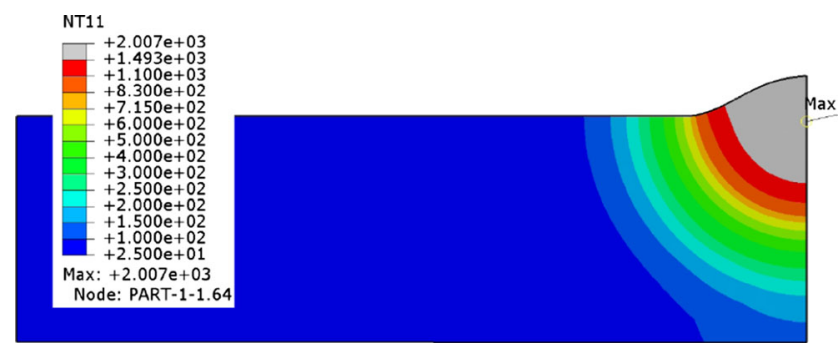

Temp $\left({ }^{\circ} \mathrm{C}\right)$

Fig. 13 The 2D axi-symmetric model and predicted temperature distribution of the fusion zone

is essential to develop a model which can accurately predict the thermo-mechanical behaviour of the fusion zone with less calculation time. If the $2 \mathrm{D}$ model can be effectively employed to predict the weld temperature distribution and residual stress, the significant amount of computational time and cost involved in 3D simulation can be avoided.

\subsection{Comparison of obtained results}

Figure 14 presents the simulated results of both the 2D and 3D models for peak temperature distribution on weld surface versus distance from the weld centre line. The graphs are generated after the temperature of fusion zone reach a quasi-steady state. It can be seen that pick temperatures of 2D model are marginally higher than that of 3D model for the points closer to weld centre line $\left(1901^{\circ} \mathrm{C}\right.$ for $2 \mathrm{D}$, and $1832^{\circ} \mathrm{C}$ for $\left.3 \mathrm{D}\right)$. This is because there is not heat transfer calculation in $\mathrm{z}$ direction in $2 \mathrm{D}$ model; hence, a higher peak temperature is predicted in $2 \mathrm{D}$ models compare to that in 3D model.

Figure $15 \mathrm{a}, \mathrm{b}$ shows the residual stress results of both $2 \mathrm{D}$ and 3D models in transverse and longitudinal directions. As can be seen in Fig. 15a, the average transverse residual stresses in HAZ are higher in 3D model than those in $2 \mathrm{D}$ model (212 $\mathrm{MPa}$ in 3D model to $165 \mathrm{MPa}$ in 2D model). However, the differences between longitudinal direction

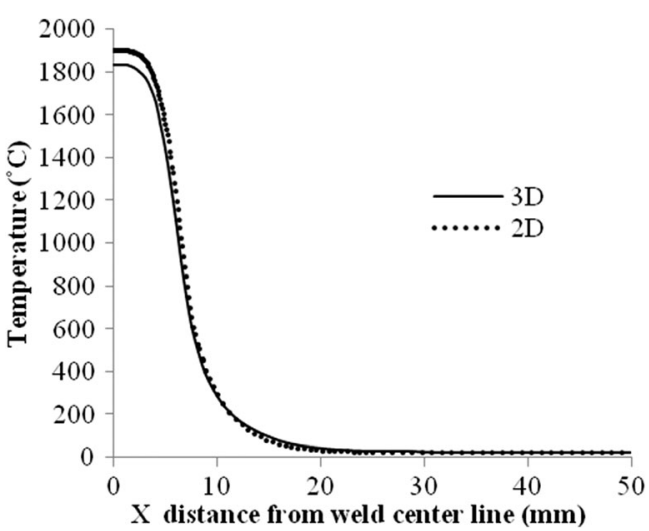

Fig. 14 Comparison between the thermal histories at weld surface computed with the $3 \mathrm{D}$ and $2 \mathrm{D}$ models 
Fig. 15 Comparison of the residual stresses calculated with the $2 \mathrm{D}$ and $3 \mathrm{D}$ models in transverse direction (a) and longitudinal direction (b)

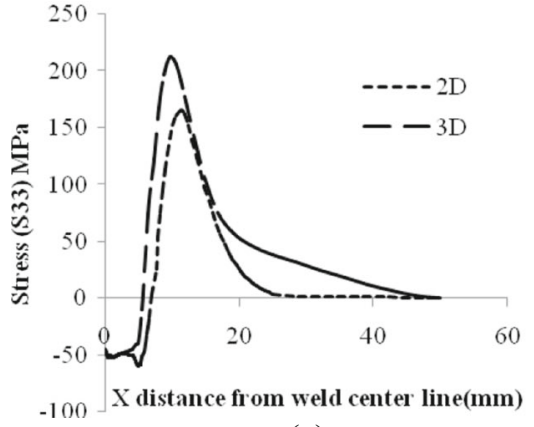

(a)

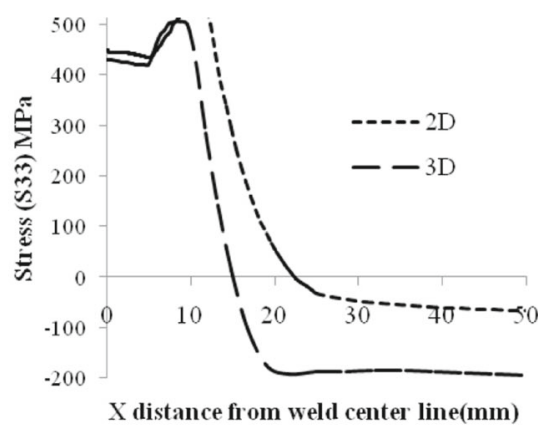

(b) residual stresses of both $2 \mathrm{D}$ and $3 \mathrm{D}$ models in HAZ are very small (504 $\mathrm{MPa}$ in $3 \mathrm{D}$ model to $530 \mathrm{MPa}$ in $2 \mathrm{D}$ model), and the $2 \mathrm{D}$ stress prediction is found to be in close agreement with $3 \mathrm{D}$ model. It is known that the longitudinal residual stresses are of the greater importance than the other stresses due to their higher magnitude. Therefore, 2D model can accurately predict the thermal cycles and residual stresses inside fusion zone and HAZ. The results of both the temperature fields and the residual stress distribution suggest that it is feasible and reasonable to conduct the thermal analysis and the mechanical analysis for the APIX65 steel plates using a 2D axi-symmetric model.

\section{Conclusions}

A new heat source distribution for SAW welding is defined in this research. A 2D axi-symmetric and 3D FE models have been developed for predicting and analysing the fusion zone temperature distribution and residual stress in submerged arc welding. The following conclusions can be drawn from the present study:

- The two Goldak's double ellipsoidal heat sources show that using both heat sources for fusion zone, and reinforcement zone can result in significant improvement for fusion zone and HAZ geometry prediction. Considering such heat source for welding with high reinforcement zone can be an appropriate approach to predict more accurate FEA results.

- There is a reasonable agreement between the predicted and the measured fusion zone geometry that verifies the validity of the employed $2 \mathrm{D}$ axi-symmetric and $3 \mathrm{D} \mathrm{FE}$ models. Using 3D model, the detailed information of thermal history and residual stress fields can be obtained. The 3D model can provide more accurate thermal history and stress distributions; however, a significant amount of computational time can be saved by employing 2D model.

- The longitudinal stresses are found to be greater than the other directional stress and hence need to be completely considered during welding of APIX65 in order to avoid transverse cracks.

- It is shown that thermal gradient is higher through the thickness than that of the specimen width; therefore, thickness is found to have greater importance than width in cooling of the fusion zone.

Open Access This article is distributed under the terms of the Creative Commons Attribution 4.0 International License (http:// creativecommons.org/licenses/by/4.0/), which permits unrestricted use, distribution, and reproduction in any medium, provided you give appropriate credit to the original author(s) and the source, provide a link to the Creative Commons license, and indicate if changes were made.

\section{References}

1. Gunaraj V, Murugan N (2000) Prediction and optimization of weld bead volume for the submerged arc process-Part 1. Weld J 79: 286-294

2. Pathak A, Datta G (2004) Three-dimensional finite element analysis to predict the different zones of microstructure in submerged arc welding. Proc Inst Mech Eng B J Eng Manuf 218:269-280

3. Esfahani MN, Coupland J, Marimuthu S (2015) Numerical simulation of alloy composition in dissimilar laser welding. J Mater Process Technol 224:135-142

4. Esfahani R, Coupland J, Marimuthu S (2014) Microstructure and mechanical properties of a laser welded low carbon-stainless steel joint. J Mater Process Technol 214(12):2941-2948

5. Chakraborty N (2009) The effects of turbulence on molten pool transport during melting and solidification processes in continuous conduction mode laser welding of copper-nickel dissimilar couple. Appl Therm Eng 29:3618-3631

6. He X, Fuerschbach P, DebRoy T (2003) Heat transfer and fluid flow during laser spot welding of 304 stainless steel. J Phys D Appl Phys 36:1388

7. Hu Y, He X, Yu G, Ge Z, Zheng C, Ning W (2012) Heat and mass transfer in laser dissimilar welding of stainless steel and nickel. Appl Surf Sci 258:5914-5922

8. Li L, Eghlio R, Marimuthu S (2011) Laser net shape welding. CIRP Ann Manuf Technol 60:223-226

9. Phanikumar G, Chattopadhyay K, Dutta P (2001) Modelling of transport phenomena in laser welding of dissimilar metals. Int $\mathrm{J}$ Numer Methods Heat Fluid Flow 11:156-174 
10. Wei P, Chung F (2000) Unsteady Marangoni flow in a molten pool when welding dissimilar metals. Metall Mater Trans B 31: 1387-1403

11. Yaghi AH, Hyde TH, Becker AA, Sun W (2013) Finite element simulation of residual stresses induced by the dissimilar welding of a P92 steel pipe with weld metal IN625. Int J Press Vessel Pip 111112:173-186

12. Youtsos A, Katsareas DE. (2005) Residual stress prediction in dissimilar metal weld pipe joints using the finite element method. Materials Science Forum: Trans Tech Publ. p. 53-61.

13. Ranjbarnodeh E, Serajzadeh S, Kokabi A, Fischer A (2012) Prediction of temperature distribution in dissimilar arc welding of stainless steel to carbon steel. Proc Inst Mech Eng B J Eng Manuf 226:117-125

14. Wen S, Hilton P, Farrugia D (2001) Finite element modelling of a submerged arc welding process. J Mater Process Technol 119:203-209

15. Mahapatra M, Datta G, Pradhan B, Mandal N (2006) Threedimensional finite element analysis to predict the effects of SAW process parameters on temperature distribution and angular distortions in single-pass butt joints with top and bottom reinforcements. Int J Press Vessel Pip 83:721-729

16. Sharma A, Chaudhary AK, Arora N, Mishra BK (2009) Estimation of heat source model parameters for twin-wire submerged arc welding. Int J Adv Manuf Technol 45:1096-1103

17. Kiran D, Basu B, Shah A, Mishra S, De A (2010) Probing influence of welding current on weld quality in two wire tandem submerged arc welding of HSLA steel. Sci Technol Weld Join 15:111-116

18. Anawa EM, Olabi AG (2008) Control of welding residual stress for dissimilar laser welded materials. J Mater Process Technol 204:22-33

19. Mai TA, Spowage AC (2004) Characterisation of dissimilar joints in laser welding of steel-kovar, copper-steel and copper-aluminium. Mater Sci Eng A 374:224-233

20. Missori S, Koerber C (1997) Laser beam welding of austeniticferritic transition joints. Weld J 76:125-134

21. Sun Z, Ion J (1995) Laser welding of dissimilar metal combinations. J Mater Sci 30:4205-4214

22. Torkamany M, Tahamtan S, Sabbaghzadeh J (2010) Dissimilar welding of carbon steel to 5754 aluminum alloy by Nd: YAG pulsed laser. Mater Des 31:458-465

23. Rosenthal D (1941) Mathematical theory of heat distribution during welding and cutting. Weld J 20:220-234

24. Goldak J, Chakravarti A, Bibby M (1984) A new finite element model for welding heat sources. Metall Trans B 15:299-305

25. Andersson B (1978) Thermal stresses in a submerged-arc welded joint considering phase transformations. J Eng Mater Technol 100: 356-362

26. Marimuthu S, Eghlio R, Pinkerton A, Li L (2013) Coupled computational fluid dynamic and finite element multiphase modeling of laser weld bead geometry formation and joint strengths. J Manuf Sci Eng 135:011004

27. Hibbitt K. (2002) ABAQUS/Standard: user's manual: version 6.3: Hibbitt, Karlsson \& Sorensen.

28. Deng D (2009) FEM prediction of welding residual stress and distortion in carbon steel considering phase transformation effects. Mater Des 30:359-366
29. Deng D, Murakawa H (2008) Finite element analysis of temperature field, microstructure and residual stress in multi-pass buttwelded 2.25 Cr-1Mo steel pipes. Comput Mater Sci 43:681-695

30. Michaleris P, DeBiccari A (1997) Prediction of welding distortion. Weld J 76:172s

31. Kim W-H, Fan H, Na S-J (1997) Effect of various driving forces on heat and mass transfer in arc welding. Numerical Heat Transfer, Part A Applications 32:633-652

32. Esfahani MN, Coupland J, Marimuthu S (2015) Microstructural and mechanical characterisation of laser-welded high-carbon and stainless steel. Int J Adv Manuf Technol 80:1449-1456

33. Hashemi S, Mohammadyani D (2012) Characterisation of weldment hardness, impact energy and microstructure in API X65 steel. Int J Press Vessel Pip 98:8-15

34. Moradpour MA, Hashemi SH, Khalili K. Machine vision implementation for off-line measurement of weld bead geometry iN API X65 pipeline steel.

35. Zhang W, Roy G, Elmer J, DebRoy T (2003) Modeling of heat transfer and fluid flow during gas tungsten arc spot welding of low carbon steel. J Appl Phys 93:3022-3033

36. British Standards. BS EN 10130:2006 Cold rolled low carbon steel flat products for cold forming. Technical delivery conditions. BS EN 10130:2006: British Standards; 2006.

37. Bang I, Son Y, Oh K, Kim Y, Kim W (2002) Numerical simulation of sleeve repair welding of in-service gas pipelines. Weld J-New York 81:273s-282s

38. Pahkamaa A, Wärmefjord K, Karlsson L, Söderberg R, Goldak J (2012) Combining variation simulation with welding simulation for prediction of deformation and variation of a final assembly. $\mathrm{J}$ Comput Inf Sci Eng 12:021002

39. Forouzan M, Nasiri SM, Mokhtari A, Heidari A, Golestaneh S (2012) Residual stress prediction in submerged arc welded spiral pipes. Mater Des 33:384-394

40. Anca A, Cardona A, Risso J, Fachinotti VD (2011) Finite element modeling of welding processes. Appl Math Model 35:688-707

41. Kiran DV, Basu B, Shah AK, Mishra S, De A (2011) Threedimensional heat transfer analysis of two wire tandem submerged arc welding. ISIJ Int 51:793-798

42. Mandal N, Adak M (2001) Fusion zone and HAZ prediction through 3-D simulation of welding thermal cycle. J Mech Behav Mater 12:401-414

43. Akbari D, Sattari-Far I (2009) Effect of the welding heat input on residual stresses in butt-welds of dissimilar pipe joints. Int J Press Vessel Pip 86:769-776

44. Francis J, Bhadeshia H, Withers $P$ (2007) Welding residual stresses in ferritic power plant steels. Mater Sci Technol 23:1009-1020

45. Kong F, Kovacevic R (2012) Development of a comprehensive process model for hybrid laser-arc welding. Welding processes Intech, New York

46. Xu S, Wang W (2013) Numerical investigation on weld residual stresses in tube to tube sheet joint of a heat exchanger. Int J Press Vessel Pip 101:37-44

47. Attarha M, Sattari-Far I (2011) Study on welding temperature distribution in thin welded plates through experimental measurements and finite element simulation. J Mater Process Technol 211:688-694 